\title{
SAÚDE COMO ESCOLHA POLÍTICA: SRAG E SUBNOTIFICAÇÃO NAS CIDADES SUL MINEIRAS
}

\author{
HEALTH AS A POLITICAL CHOICE: SARS AND SUBNOTIFICATION IN THE SOUTHERN CITIES \\ OF MINAS GERAIS STATE
}

Júlia Marchesin Caetano ${ }^{\mathbf{A}}$

Flávio Henrique Calheiros Casemiro ${ }^{\mathrm{B}}$

\author{
${ }^{\text {A }}$ Universidade Estadual Paulista (UNESP), São Paulo, SP, Brasil

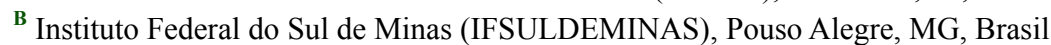

Recebido em: 31/01/2021 | 28/04/2021 DOI: $10.12957 /$ tamoios.2021.57476

Correspondência para: Júlia Marchesin Caetano (julia_marchesin@hotmail.com)

\begin{abstract}
Resumo
A discussão sobre a COVID-19 no contexto brasileiro tem trazido diversos fatores agravantes da forma como a doença tem sido tratada na esfera pública. Apesar de se tratar de uma pandemia, onde o desafio de enfrentamento é mundial, a dimensão da tragédia sanitária brasileira só pode ser compreendida em sua relação com a forma como o governo se posicionou e elaborou suas estratégias de enfrentamento. A desinformação sistemática, a baixa testagem e a subnotificação dos casos são alguns dos elementos que contribuíram para se chegar aos números alarmantes da pandemia no Brasil. Partindo do pressuposto de que saúde configura-se como uma escolha política, o objetivo central deste estudo, por sua vez, é analisar a relação entre as chamadas Síndromes Respiratórias Agudas Graves (SRAG), principalmente as "não especificadas", como mecanismo deliberado que se insere no processo de subnotificação de casos no Brasil e, mais especificamente, na região sul-mineira.
\end{abstract}

Palavras-chave: COVID-19; SRAG; Subnotificação; Sul de Minas; Escolha Política.

\begin{abstract}
The discussion about COVID-19 in the Brazilian context has brought several factors aggravating the way the disease has been treated in the public sphere. Despite being a pandemic, where the challenge of confrontation is worldwide, the dimension of the Brazilian health tragedy can only be understood in its relationship with the way the government has positioned itself and elaborated its coping strategies. Systematic misinformation, low testing and underreporting of cases are some of the elements that contributed to the alarming numbers of the pandemic in Brazil. Based on the assumption that health is configured as a political choice, the central objective of this study, in turn, is to analyze the relationship between the so-called Serious Acute Respiratory Syndromes (SARS), mainly the "unspecified" ones, as a deliberate mechanism that is part of the process of underreporting cases in Brazil and, more specifically, in the south of Minas Gerais.
\end{abstract}

Keywords: COVID-19; SARS; Underreporting; South of Minas; Political choice. 


\section{INTRODUÇÃO}

Um debate público profundo e complexo sobre a pandemia que assola o mundo todo e que vai ficar marcado na história da humanidade, exige muito mais que uma abordagem objetiva quanto ao seu caráter biológico ou sua capacidade de disseminação. Por mais que estejamos tratando sobre um vírus em sua assustadora característica de rápido contágio e a sua letalidade - que já ultrapassou 220 mil óbitos "oficiais", somados a outros cerca de 70 mil óbitos registrados como Síndrome Respiratória Aguda Grave "não especificada" - não podemos nos furtar de debater o campo da saúde, tendo em vista a sua dimensão política. Por conseguinte, é necessário o entendimento da saúde enquanto escolha política.

A Declaração Universal dos Direitos Humanos das Nações Unidas (1948), em seu artigo 25, apresenta uma visão bastante abrangente quanto ao significado do que caracteriza ser um ser humano. O texto define que a dignidade do ser humano, dentre vários aspectos, dependeria do "direito a um nível de vida capaz de lhe assegurar (...) saúde e bem-estar". Para tanto, alguns aspectos são considerados básicos para conferir tais premissas, como é o caso da "alimentação, vestuário, habitação, assistência médica e serviços sociais indispensáveis". Diante de adversidades o texto prevê que os "seres humanos têm direito à segurança em caso de desemprego", e mais do que isso, diante da "perda dos meios de subsistência em circunstâncias fora de controle", teriam o direito de receber compensações para o enfrentamento e garantia da dignidade (DUDH 2009, p. 13).

De acordo com o Relatório Tricontinental de Pesquisa Social, lideranças mundiais reuniram-se na sede da ONU, em setembro de 2019, para assumir uma espécie de promessa de uma assistência universal à saúde até 2030. A diplomata e médica norueguesa Gro Harlem Brundtland, que presidia a Organização Mundial de Saúde (OMS), disse que "a assistência médica não poderia ser deixada nas mãos do livre mercado (...). Há uma necessidade urgente de financiamento público. Cortar os recursos para a saúde é um grande erro”. Esses líderes mal sabiam o grande desafio de proporções globais que teriam que enfrentar, poucos meses depois. No mesmo sentido, o atual chefe da OMS, o etíope Tedros Adhanom também enfatizou que "a saúde é uma escolha política" (ITPS, junho 2020).

O debate mundial sobre as decisões políticas em torno da saúde, por conseguinte, adquire uma nova dimensão com a pandemia da COVID-19, no ano de 2020. Determinadas escolhas e diretrizes políticas no âmbito da saúde pública e seu investimento (financeiro e organizacional), definem a diferença entre milhares de óbitos em alguns casos, e centenas de 
milhares de óbitos, em outros. Números assustadores e projeções estatísticas macabras têm deixado (ou pelo menos deveria deixar) perplexa a sociedade brasileira.

O problema é quando números e dados estatísticos assumem um papel mais importante do que a própria vida humana e o sofrimento daqueles que perderam seus familiares e pessoas queridas diante dessa pandemia. Além disso, assistimos um processo inquietante de naturalização e normalização desses dados cotidianos de contaminados e mortos. Não é uma mera coincidência o fato de que os países que estão sofrendo as piores consequências da pandemia, também sejam, justamente, os países mais alinhados ao projeto neoliberal, que descartaram as recomendações da OMS, como é o caso dos EUA e Brasil.

Nessa perspectiva, talvez o caso mais dramático seria o brasileiro, onde o Governo de Jair Bolsonaro menospreza a epidemia e seus efeitos devastadores, fazendo uma campanha permanente a favor da manutenção e retomada da atividade econômica, praticamente sem restrições. Com isso, o governo brasileiro não só deixa de assistir sua população em um momento crítico, negligenciando aos grupos mais vulneráveis socialmente, às condições mínimas de garantia de sobrevivência e dignidade humana, mas também se coloca em uma posição negacionista diante da pandemia, ora negando sua periculosidade, ora manipulando seus números para justificar suas decisões político-ideológicas. Subjugar a vida humana concreta aos números e, principalmente, utilizar de estratégias de manipulação desses números como mecanismo de escamoteamento da realidade para fins políticos, sem dúvida alguma, caracterizam decisões e escolhas políticas.

É neste sentido que estamos chamando a atenção para as chamadas Síndromes Respiratórias Agudas Graves (SRAG). O objetivo deste artigo, por sua vez, é apresentar uma análise quantitativa e qualitativa das SRAG, buscando relacioná-las ao debate em torno da COVID-19. Outrossim, é importante demonstrar a forma como o "diagnóstico" e caracterização dessas síndromes podem representar um mecanismo de adulteração dos números efetivos referentes à pandemia, ou seja, como instrumento para maquiar a subnotificação de casos da COVID-19 no Brasil e, no nosso caso mais específico, no Sul de Minas.

\section{SUBNOTIFICAÇÃO}

A vigilância em saúde se relaciona "às práticas de atenção e promoção da saúde dos cidadãos e os mecanismos adotados para prevenção de doenças" (FIOCRUZ, online), ou seja, é uma área que envolve diversos campos e temas, desde planejamento e políticas públicas à monitoramento, avaliação e controle de agentes etiológicos. No atual momento, o setor da vigilância que mais se destaca é a vigilância epidemiológica, que identifica, notifica e age para controlar epidemias em territórios específicos. Outra atribuição essencial desse sistema é a divulgação dos dados coletados pelos monitoramentos ao público geral.

Portanto, é dentro deste sistema que se pode ter acesso aos dados oficiais das epidemias existentes em cada território, que vão além da pandemia do novo coronavírus e 
incluem doenças como HIV/Aids, Hepatites Virais, Tuberculose, Gripe, entre outras. O que indica uma característica muito importante da subnotificação: ela não é exclusiva da pandemia de COVID-19, e já foi observada em outras situações de atenção epidemiológica. "A notificação é a comunicação da ocorrência de determinadas doenças ou agravos à saúde por parte dos profissionais de saúde, ou qualquer cidadão, à autoridade sanitária, para fins de adoção de medidas de intervenção pertinentes" (MEGDA, BONAFÉ, 2013). No caso de doenças transmissíveis, a notificação é compulsória, e a relação de doenças as quais esses dados se relacionam está disponível para consulta no portal do Ministério da Saúde.

Todavia, o objetivo deste artigo é compreender a subnotificação como um agravo para o enfrentamento às epidemias. A subnotificação se estabelece quando se notifica menos do que seria esperado ou devido, sendo incapaz de refletir a realidade da doença nos territórios. De acordo com pesquisas desenvolvidas por Megda e Bonafé (2013), a subnotificação atinge o país todo, sendo mais grave em estados do norte e nordeste. HIV/Aids por exemplo apresenta índices médios de subnotificação que variam de $26 \%$ a $42 \%$ nos estados de Alagoas e no Rio de Janeiro entre 1996 e 1999, o que demonstra que esta questão se mantém preocupante há pelo menos 20 anos.

Outra armadilha que pode atrapalhar a mensuração correta dos dados são os atrasos em notificação. Um problema comum é o sistema difuso de recolhimento dessas informações. Cada país possui uma forma e uma agencia responsável pela coleta desses dados, que por sua vez, cada cidade/estado tem um meio de notificação e seu próprio processo de atualização, que pode não coincidir com as datas e horários nos quais outros locais divulgam suas informações (BACKHAUS, 2020). A seguir passaremos a delinear o funcionamento do sistema brasileiro de vigilância epidemiológica.

\section{PANORAMA DA SRAG}

De acordo com estudos recentes, elaborados por pesquisadores da Fundação Oswaldo Cruz (FioCruz) ${ }^{1}$ em conjunto a contribuições de outras instituições, o ano de 2020 tem apresentado alta considerável em número de hospitalizações por Síndrome Respiratória Aguda Grave (SRAG) a partir da $9^{a}$ semana epidemiológica, na qual o primeiro caso oficial de COVID-19 foi registrado (BASTOS et al, 2020). Comparações com o mesmo período têm sido feitas em até 10 anos anteriores, dado que a notificação da Síndrome teve início com a epidemia de Influenza em 2009. Sendo assim, a partir da aparição do novo coronavírus em território brasileiro, é significativo o aumento observado, tornando-se relevante tratar desses dados em comparação com os dados oficiais da COVID-19, argumentando que, a partir da baixa taxa de testes realizados, temos um cenário de subnotificação, agravado também, pelos atrasos que a atualização do sistema sofre, se provando lento o processo de notificação e testagem.

O cenário brasileiro é heterogêneo tanto no tocante à evolução da epidemia quanto no acesso à saúde, uma vez que temos um território de proporções continentais, com diferentes padrões 
de distribuição da população, de condições de transporte (vias de acesso, disponibilidade e custos), desigualdades de renda e educação (NIQUINI; et al, 2020, p.2).

O sistema de notificação e vigilância epidemiológica tem sua importância elevada quando tratamos de uma doença como a COVID-19, dada sua singularidade, rápida disseminação e com protocolos primários de tratamento desenvolvidos no curto período em que a doença trouxe consequências devastadoras para o mundo. De acordo com a Lei Federal $n^{\circ} 8.080 / 1990$, em seu Art. $6^{\circ}$, um sistema de vigilância epidemiológica deve dispor de

um conjunto de ações que proporciona o conhecimento, a detecção ou prevenção de qualquer mudança nos fatores determinantes e condicionantes de saúde individual ou coletiva, com a finalidade de recomendar e adotar as medidas de prevenção e controle das doenças ou agravos (BRASIL, 1990).

Portanto, é muito relevante o uso dessas plataformas no auxílio ao combate ao espraiamento de doenças transmissíveis no país, dado que é a partir destes levantamentos que as análises podem ser elaboras, e consequentemente, decisões possam ser tomadas para a proteção da saúde dos indivíduos. No Brasil, as notificações da SRAG são feitas através da plataforma SINAN e do Sistema de Vigilância da Gripe (SIVEP-Gripe) ${ }^{2}$, ambas de responsabilidade do Ministério da Saúde, e criadas em 2009 para monitorar a epidemia de Influenza.

A SRAG consiste no diagnóstico dado a uma hospitalização que apresente um quadro específico de sintomas que, por sua vez, são semelhantes aos da gripe, caracterizada por febre, dor de cabeça, calafrios, dores musculares, tosse seca e dificuldade para respirar. Estes mesmos sintomas podem ser causados pelos coronavírus, em especial pelo SARS-CoV-2. A diferença entre as duas síndromes é definida de acordo com o protocolo ministerial descrito no quadro a seguir:

QUADRO 1 - Definição de caso e notificação de SRAG e COVID-19 pelo protocolo do Ministério da Saúde.

\begin{tabular}{|c|c|c|c|}
\hline Definição & Sintomas & Em crianças & Em idosos \\
\hline $\begin{array}{l}\text { Síndrome } \\
\text { Gripal (SG) }\end{array}$ & $\begin{array}{l}\text { Quadro respiratório agudo } \\
\text { Febre } \\
\text { Tosse (ou) } \\
\text { Coriza (ou) } \\
\text { Dificuldade respiratória }\end{array}$ & Obstrução nasal & $\begin{array}{l}\text { Febre pode estar ausente } \\
\text { Síncope } \\
\text { Confusão mental } \\
\text { Sonolência excessiva } \\
\text { Irritabilidade } \\
\text { Inapetência }\end{array}$ \\
\hline
\end{tabular}




\begin{tabular}{|c|c|c|}
\hline $\begin{array}{l}\text { Síndrome } \\
\text { Respiratória } \\
\text { Aguda } \\
\text { Grave } \\
\text { (SRAG) }\end{array}$ & $\begin{array}{l}\text { Dispneia/desconforto respiratório (ou) } \\
\text { Pressão persistente no tórax (ou) } \\
\text { Saturação de O } 2 \text { menor que } 95 \% \text { em ar } \\
\text { ambiente (ou) } \\
\text { Coloração azulada dos lábios ou rosto }\end{array}$ & $\begin{array}{l}\text { Batimentos de asa de } \\
\text { nariz } \\
\text { Cianose } \\
\text { Tiragem intercostal } \\
\text { Desidratação } \\
\text { Inapetência }\end{array}$ \\
\hline
\end{tabular}

Fonte: Ministério da Saúde, 2020.

Nesse sentido, a SRAG pode ser diagnosticada através de exame clínico e laboratorial, com a realização de testes que identificam o agente causador da síndrome (quadro 2). No Brasil, existem 5 classificações usadas pelo SIVEP-Gripe para diagnóstico final da SRAG: (1) causado por vírus da Influenza, (2) causado por outro tipo de vírus, (3) causado por outro agente etiológico, (4) não especificado, (5) causado pelo vírus da COVID-19 - até fevereiro de 2019 eram apenas 4, excluindo-se o novo coronavírus.

Os casos de COVID-19 são notificados em ambas as plataformas ministeriais: quando o paciente apresenta sintomas leves que geralmente não levam a internação, o caso é notificado como Síndrome Gripal. Caso o paciente apresente os sintomas que caracterizam a Síndrome Respiratória Aguda Grave, ele será testado e seu caso será notificado de outra forma, através de formulário referente à SRAG. Em ambos os casos, é protocolo a realização de testes para confirmação.

Portanto, é somente mediante realização de testes laboratoriais (sejam eles testes rápidos, sorologia, PCR, dentre outros), que é possível distinguir qual agente causou a síndrome. $\mathrm{O}$ quadro a seguir apresenta os critérios para o diagnóstico:

QUADRO 2 - Critérios para confirmação de casos de COVID-19 de acordo com protocolo do Ministério da Saúde.

\begin{tabular}{|l|l|}
\hline Critério & Como é feito o diagnóstico \\
\hline Laboratorial & $\begin{array}{l}\text { TESTE Biologia molecular: RT-PCR em tempo real, detecção do vírus } \\
\text { SARS-CoV-2, Influenza ou VSR) }\end{array}$ \\
\hline $\begin{array}{l}\text { TESTE Imunológico: teste rápido ou sorologia clássica para detecção de } \\
\text { anticorpos) }\end{array}$ \\
\hline $\begin{array}{l}\text { Clínico-epidemiol } \\
\text { ógico }\end{array}$ & $\begin{array}{l}\text { Histórico de contato próximo ou domiciliar, nos últimos } 7 \text { dias antes do } \\
\text { aparecimento dos sintomas, com caso confirmado laboratorialmente para } \\
\text { COVID-19 e para o qual não foi possível realizar a investigação laboratorial } \\
\text { específica. }\end{array}$ \\
\hline
\end{tabular}

Fonte: Ministério da Saúde, 2020. 
De acordo com o Ministério da Saúde, os casos suspeitos de SG e SRAG devem ser notificados dentro do prazo de 24 horas a partir da suspeita inicial do caso ou do óbito. $\mathrm{O}$ processo de notificação consiste no preenchimento de uma ficha referente a cada paciente na qual, além de informações pessoais, é necessário inserir quais os sintomas que o paciente apresentou, quais exames foram feitos, quais as doenças pré-existentes, frequência de vacinação, evolução do caso, dentre outros. A ficha é de responsabilidade da unidade hospitalar na qual o paciente deu entrada: o responsável médico a preenche e ela é encaminhada para a administração para que seja lançada no SIVEP-Gripe. Após este processo, os dados coletados são divulgados abertamente através do Open Data SUS, porém, ainda não se observou uma frequência de atualizações dos casos notificados como SRAG ${ }^{3}$.

Com base nas informações da Figura 1, pode-se visualizar o funcionamento do sistema de notificação da SRAG, destacando-se os processos referentes ao diagnóstico e aos prazos estipulados para notificar e encerrar o caso (podendo chegar a 60 dias). Com o surgimento da COVID-19 e suas características sendo inclusas dentro das SRAGs, o processo tem necessidade de se tornar mais rápido, tanto para efeito de segurança do paciente, como para o levantamento adequado do número de pessoas acometidas pela doença, traçando o panorama da situação no país. Porém, falhas no sistema de diagnóstico e notificação têm trazido obstáculos para uma apuração mais efetiva da realidade brasileira frente a essa nova crise de proporções globais.

FIGURA 1 - Organização do sistema de notificação e investigação da Síndrome Respiratória Aguda Grave (SRAG) de 2014 a 2016. 


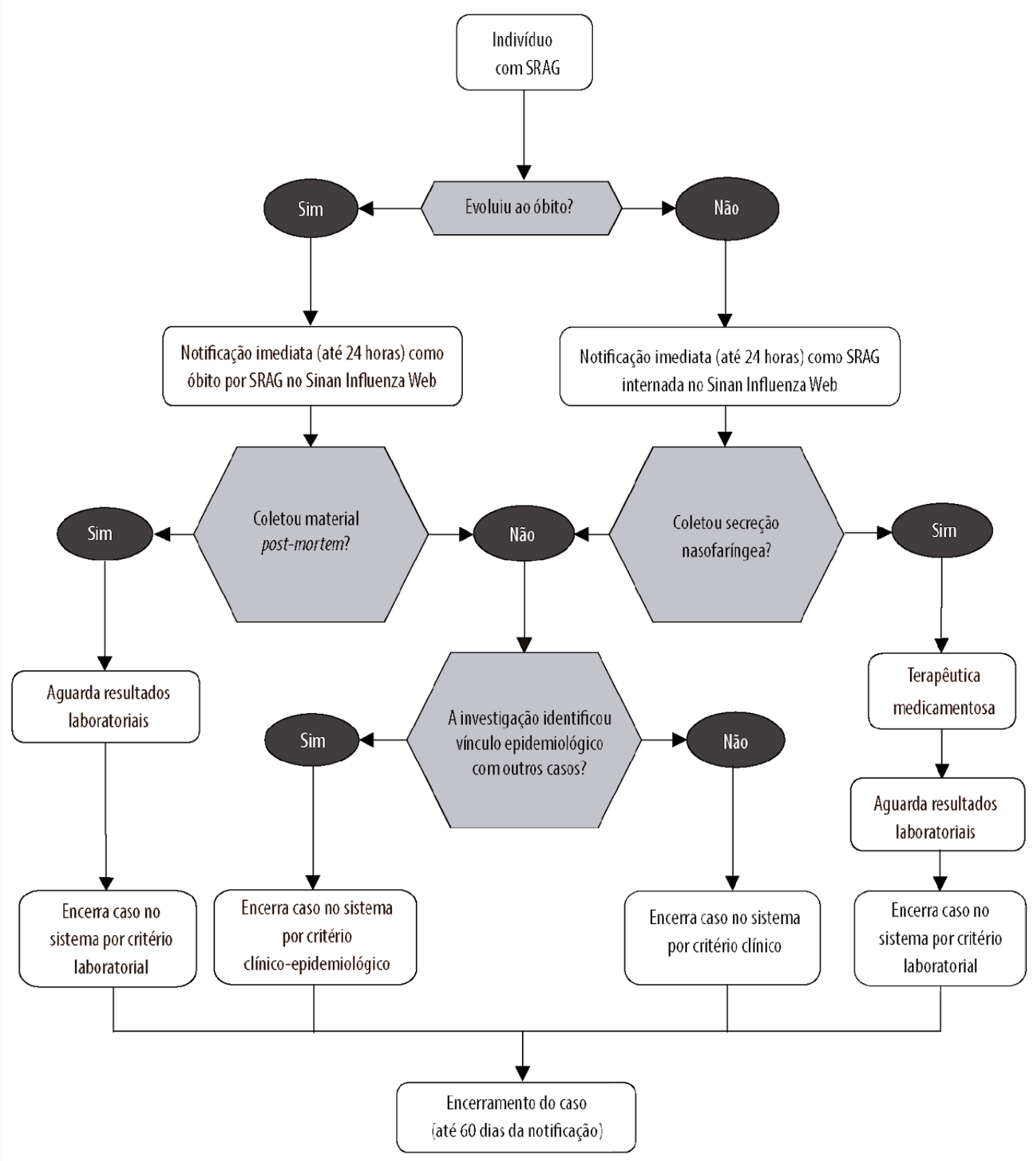

Fonte: Ministério da Saúde, 2014; 2016. Extraído de: RIBEIRO; SANCHEZ, 2020, p.3.

Dado o início da contaminação da COVID-19 em território brasileiro, o sistema de vigilância epidemiológica precisou adaptar mecanismos para monitoramento da doença, e para isso, em um primeiro momento, notificavam-se os casos do novo coronavírus através do sistema REDCap, que operou entre Janeiro e Março de 2020, e pelo e-SUS-VE, que agregaram seus dados posteriormente ao SIVEP-Gripe (DE SOUZA, et al, 2020, p. 857).

Apesar de avaliações positivas (RIBEIRO e SANCHEZ, 2020) deste sistema quando observado nos casos de outras epidemias - classificado, dentre outros parâmetros, com baixa 
inconsistência e de grande utilidade -, ele ainda sofre muitas irregularidades em relação à apuração mais precisa de todos os aspectos que envolve os casos. Dada a singularidade do novo coronavírus, e a sobrecarga das infraestruturas de saúde, muitos dados vão se perdendo ao longo do processo. Por isso a importância de uma avaliação que preconize atributos quantitativos e qualitativos relativos ao sistema de vigilância.

Outras limitações correspondem a possibilidade de perda de amostra por falsos negativos devido ao período na qual a coleta foi realizada. Ao mesmo tempo, de acordo com publicações de pesquisadores da FioCruz (NIQUINI et al, 2020) existem eventualidades de hospitalizações por COVID-19 que não são inseridas no sistema por não apresentarem quadro clínico claro de sintomas.

Além destas questões, outro problema enfrentado pela avaliação destes dados é que, em muitos casos, a própria administração municipal de certas cidades possui um sistema próprio de notificação dos casos de COVID-19. Dessa forma, é possível que a notificação não seja feita oficialmente por meio das plataformas ministeriais, originando uma discrepância relevante entre os números.

É diante deste cenário que é importante que, junto com os dados sobre a COVID-19, sejam divulgados os casos de SRAG, em especial os de natureza não especificada. Pois, dada a precarização do número de testes realizados, existe a possibilidade de alguns números da COVID-19 estarem sendo contabilizados em outras classificações de SRAG. Para demonstrar estes processos, foram elaboradas diversas análises, estabelecendo comparativos com os mesmos períodos em anos anteriores em três níveis: nacional, estadual e municipal. Aqui chamaremos atenção para os números brasileiros, em especial os que dizem respeito à Minas Gerais.

Ressaltamos que a autonomia dos estados e municípios reflete significativamente nos resultados que podemos observar atualmente. Para além desta análise, é imprescindível observar as ações dos programas e protocolos estabelecidos por estas instituições. Um exemplo dessa política difusa é a criação dos planos estaduais, como o Plano São Paulo e o Minas Consciente, que apesar de terem o objetivo de auxiliar os municípios na tomada de decisões dependem da aderência dos mesmos aos protocolos estabelecidos. Como exemplo podemos citar São Thomé das Letras/MG, localizada no Sul de Minas, que desde o início da pandemia estabeleceu barreiras sanitárias e protocolos de lockdown, registrando o primeiro caso da contaminação em 5 de novembro de 2020, após flexibilizar a entrada de visitantes. A cidade estabeleceu medidas mais sérias que as recomendadas pelo estado, demonstrando que este método se provou eficiente para o controle do vírus na cidade.

\section{METODOLOGIA E RESULTADOS}

Os dados coletados até o momento foram resultado de um prévio levantamento de fontes disponíveis de forma acessível para a comunidade científica, tais como SIVEP-Gripe; 
Monitora Covid-19 (FioCruz); IBGE e dos boletins epidemiológicos da Secretaria de Estado de Minas Gerais. Através do processamento de dados por meio de gráficos e tabelas, foi possível usar o software livre QGis 3.12.2 para espacialização das informações coletadas, resultando em análises espaço-temporais dos efeitos da COVID-19 em território sul-mineiro. Além disso, com fins comparativos, foram inseridos infográficos autoexplicativos capazes de contribuir para visualização dessa suposta relação, bem como, ter uma dimensão mais complexa dessa problemática.

De acordo com os levantamentos obtidos na Plataforma Monitora COVID-19 da FioCruz, percebe-se que houve uma explosão nos registros de casos e mortes causados pela Síndrome Respiratória Aguda Grave (SRAG) de 2019 para 2020. No Brasil, a alta em número de casos é de mais de $2000 \%$, e em número de mortes esse crescimento é da ordem de $4000 \%$. A partir dos gráficos 1 e 2, podemos identificar esse aumento observando os gráficos comparativos, assim como a proporcionalidade de casos de SRAG: a cada 100 casos da síndrome em 2020, houve cerca de 4 com o mesmo diagnóstico em 2019 em todo o Brasil. Estas evoluções repentinas acontecem ao mesmo tempo em que a difusão da COVID-19 se intensifica no território brasileiro.

GRÁFICO 1 - Casos de SRAG no Brasil entre a $1^{\mathrm{a}}$ e $53^{\mathrm{a}}$ semanas epidemiológicas de 2019 e 2020.

\section{SRAG BRASIL}
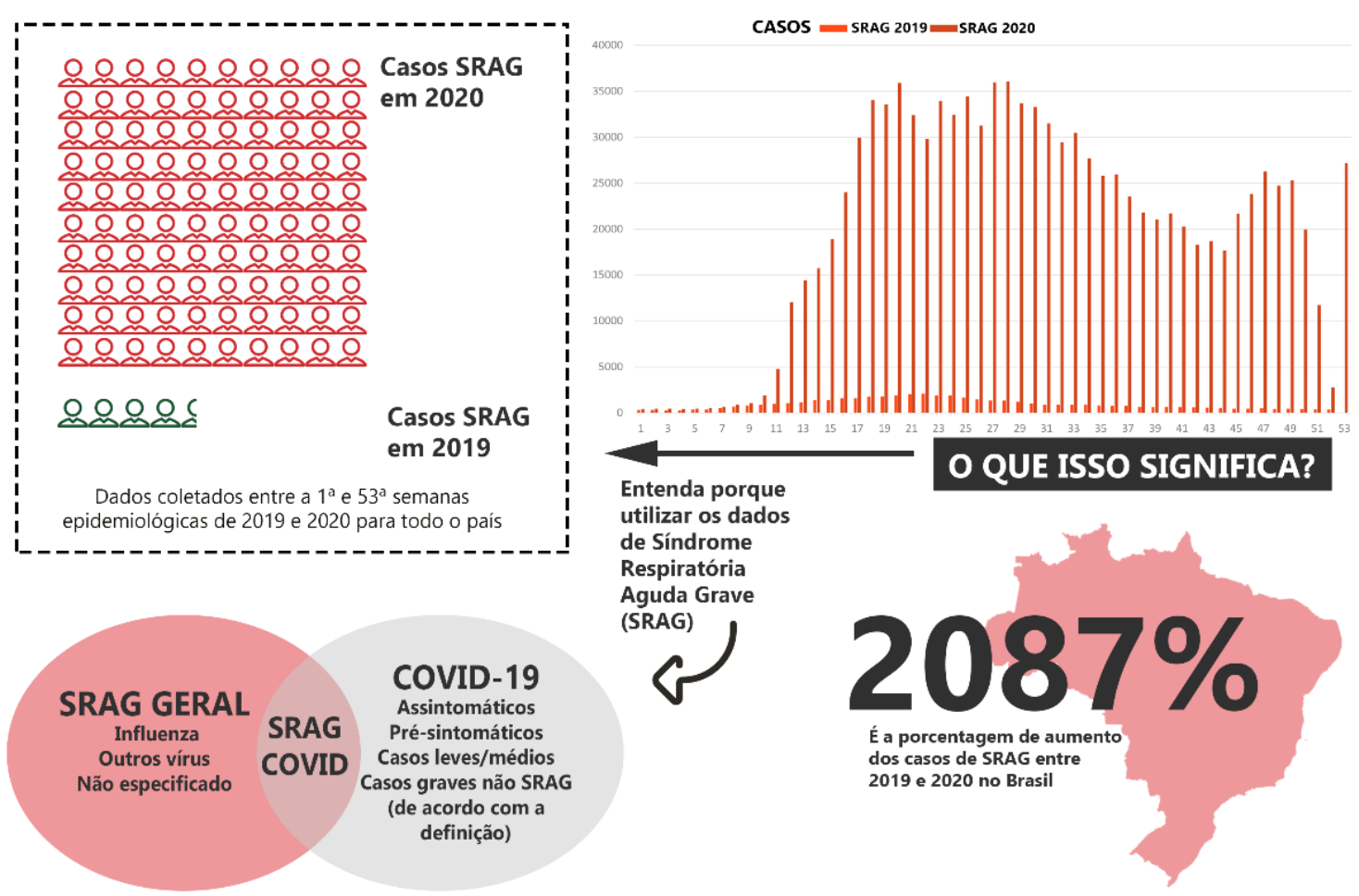
Fonte: Fundação Oswaldo Cruz, 2020. Org.: autores.

Outra observação possível vem através da variação de casos ao longo do ano de 2020. Entre as semanas 19 e 29 (Maio e Junho) o número de casos de SRAG se manteve em alta, e volta a subir a partir da semana 45 (Novembro), quando as medidas de isolamento social se tornaram mais flexíveis, e quando observou-se a volta mais expressiva das atividades comerciais. Outra alta considerável foi observada na última semana do ano, que foi de 27/12/2020 a 02/01/2021, e reflete nitidamente dois fatores: um reflexo das festas de final de ano, que contribuíram para a contaminação rápida do novo coronavírus, fato que foi seguido da menor baixa registrada em 10 meses de pandemia, se apresentando mais uma vez como evidência da subnotificação sistemática. As mesmas observações se repetem para o número de mortos.

GRÁFICO 2 - Óbitos causados por SRAG no Brasil entre a $1^{\mathrm{a}}$ e $53^{\mathrm{a}}$ semanas epidemiológicas de 2019 e 2020.

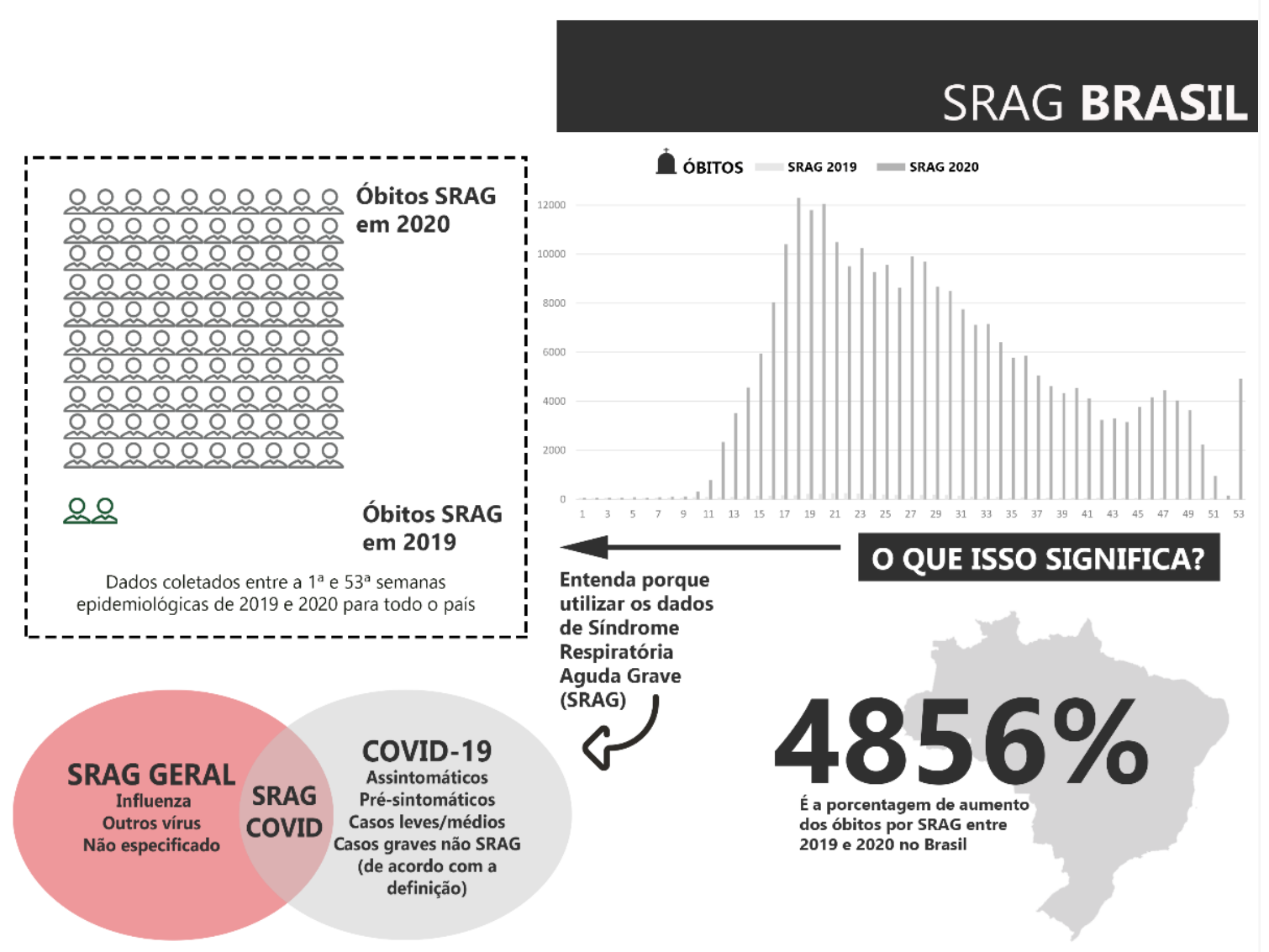

Fonte: Fundação Oswaldo Cruz, 2020. Org.: autores.

Por ser uma síndrome estudada há pelo menos 10 anos no Brasil, muitas características podem ser aplicadas às particularidades do novo coronavírus, dada a 
similaridade de sintomas, além de outros aspectos. Além disso, podemos sintetizar os dados dos últimos cinco anos para observarmos o panorama que justifica a subnotificação. Através da tabela 1 podemos perceber que a partir de 2016 temos uma estabilidade no número de casos da síndrome anualmente em Minas Gerais. Por outro lado, em 2020 temos um aumento de cerca de $2000 \%$ se compararmos à média dos últimos 4 anos. Todavia, mesmo se excluirmos as infecções confirmadas como COVID-19 em 2020 ainda temos um aumento da casa de $1000 \%$.

TABELA 1 - Comparação dos casos de SRAG no período de 2015 a 2020 em Minas Gerais.

\begin{tabular}{|c|c|c|c|c|c|c|}
\hline SRAG Minas Gerais & 2015 & 2016 & 2017 & 2018 & 2019 & 2020 \\
\hline Covid-19 & 0 & 0 & 0 & 0 & 0 & 38533 \\
\hline Influenza & 117 & 1050 & 300 & 343 & 432 & 178 \\
\hline Outros vírus respiratórios & 142 & 88 & 240 & 183 & 347 & 55 \\
\hline Outros agentes etiológicos & 7 & 20 & 17 & 9 & 17 & 3 \\
\hline Não especificado & 1134 & 3828 & 2566 & 2619 & 2995 & 44156 \\
\hline Total & 1400 & 4986 & 3123 & 3154 & 3791 & 83170 \\
\hline
\end{tabular}

Fonte: SIVEP-Gripe (2015, 2016, 2017, 2018, 2019 e 2020).

Os levantamentos publicados pelos pesquisadores da FioCruz (2020) demonstram a hipótese de que casos graves de COVID-19 venham sendo detectados pela vigilância de SRAG, porém não são especificados como causados pelo SARS-CoV-2, devido a falhas nos sistemas de testagem, coleta de amostras e demora no processamento. Essa constatação traz luz a uma possível sobrecarga do sistema de saúde. Entretanto, é preciso ter cautela no tratamento de dados. Por isso, através destes mesmos dados, foram elaboradas as comparações em nível estadual. De acordo com as informações coletadas, podemos fazer um paralelo entre os diagnósticos finais de COVID-19 e de SRAG (não especificado). Tais análises estão sintetizadas nos gráficos 3 e 4 , nos quais é possível observar a proporcionalidade de casos dessas doenças mais especificamente em Minas Gerais, entre a $1^{\text {a }}$ e $53^{\mathrm{a}}$ semanas epidemiológicas.

GRÁFICO 3 - Casos de SRAG em Minas Gerais entre a $1^{\mathrm{a}}$ e $53^{\mathrm{a}}$ semanas epidemiológicas de 2019 e 2020. 


\section{casos SRAG MINAS GERAIS}
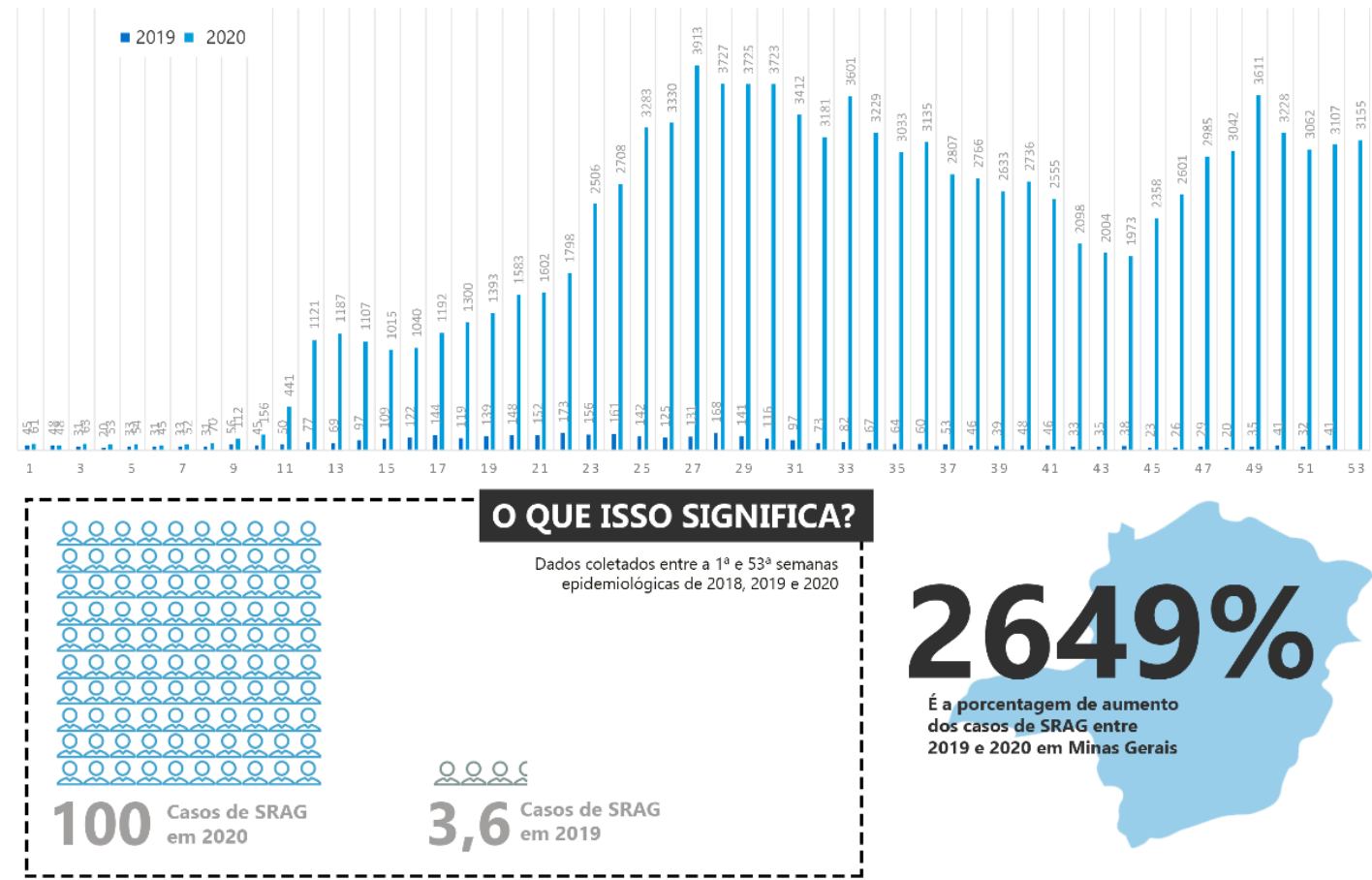

É a porcentagem de aumento dos casos de SRAG entre 2019 e 2020 em Minas Gerais

Fonte: Fundação Oswaldo Cruz, 2020. Org.: autores.

GRÁFICO 4 - Óbitos causados por SRAG em Minas Gerais entre a $1^{\mathrm{a}}$ e $53^{\mathrm{a}}$ semanas epidemiológicas de 2019 e 2020. 


\section{ómrtos SRAG MINAS GERAIS}

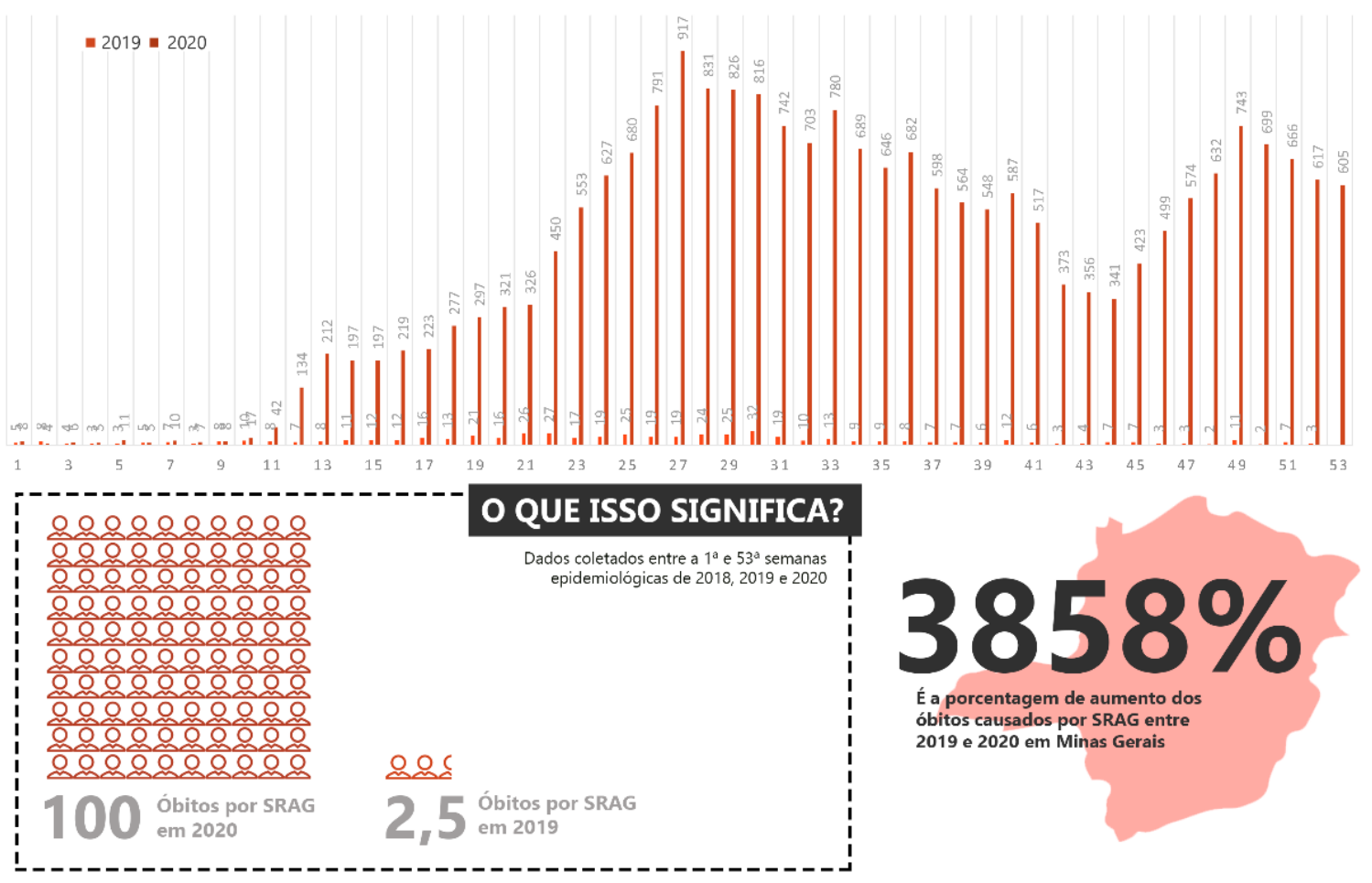

Fonte: Fundação Oswaldo Cruz, 2020. Org.: autores.

Os dados apontam, novamente, vestígios da subnotificação, agora especificamente em território mineiro. As comparações revelam que o problema da subnotificação se estende ao longo do ano de 2020, demonstrando que não houveram melhoras significativas no que tange à adequada notificação e apuração dos casos.

Por conseguinte, como foco deste artigo, tratamos principalmente destes dados sistematizados para a realidade específica da Mesorregião Sul/Sudoeste de Minas Gerais, a partir da qual foi possível apurar as diferenças entre a manifestação da SRAG em 2019 e 2020 .

Nas cidades do Sul/Sudoeste de Minas, o crescimento em número de casos de SRAG é bastante expressivo, como evidenciado na leitura da figura 2. As cidades com maiores diferenças são as mesmas que vêm apresentado alta densidade de casos de COVID-19, demonstrando, mais uma vez, a correlação entre os diagnósticos não especificados com os dos causados pelo novo coronavírus. Podemos destacar as cidades de Varginha/MG, Alfenas/MG, Poços de Caldas/MG, Itajubá/MG, Pouso Alegre/MG e São Sebastião do Paraíso/MG, nas quais o aumento do número de registros da síndrome se intensificou expressivamente. 
FIGURA 2 - Comparação entre os casos de SRAG não especificado entre 2019 e 2020 na Mesorregião Sul/Sudoeste de Minas Gerais.

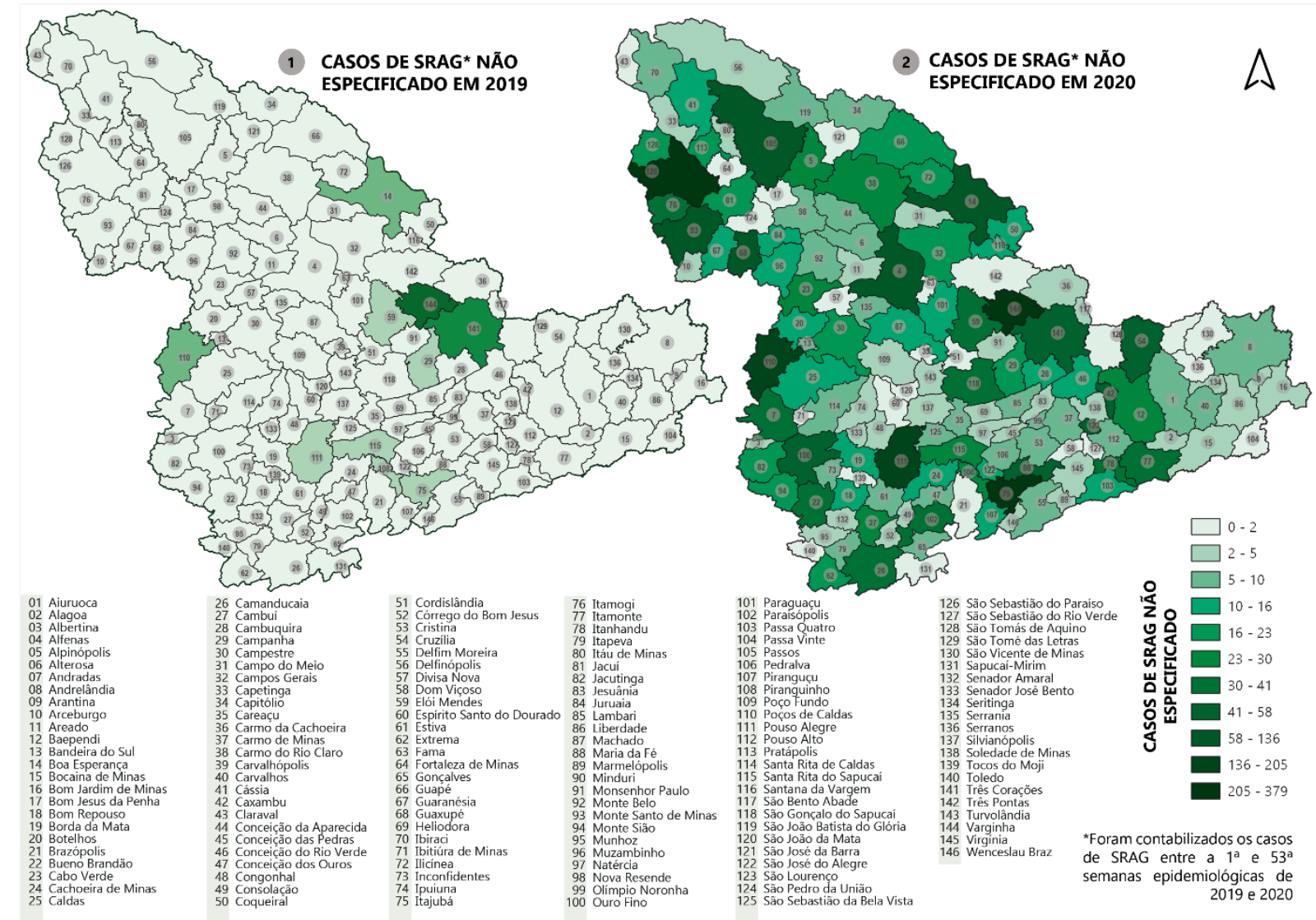

Fonte: Open Data SUS, 2020; Malha cartográfica digital IBGE, 2018; Org.: autores.

Através dos mapeamentos, é possível visualizar esta diferença, na espacialização e entendimento dos efeitos da doença a nível municipal e, principalmente, trazendo o panorama correto para o posicionamento estratégico em relação ao combate à doença.

A representação espacial de dados da SRAG no Sul de Minas Gerais aponta para a ampla diferença das manifestações da doença em dois panoramas diferentes: em 2019, no qual não haviam vestígios do surgimento da COVID-19, e no qual a SRAG compreendia casos de agravo decorrentes de infecção pela Influenza e outros vírus respiratórios, e em 2020, quando entramos em um cenário pandêmico, de proporções escalares, no qual a magnitude da disseminação do vírus SARS-CoV-2 ainda está sendo assimilada.

Assim, em 2019, temos um quadro normalizado da expressividade da SRAG, se encaixando nos mesmos parâmetros de anos anteriores, dado que desde 2009 outras 
epidemias de vírus respiratórios atingiram porções do território brasileiro. Já em 2020, a realidade é bastante diferente: os aumentos ultrapassam em mais de $1000 \%$, evidenciando que um novo elemento entrou na "soma" das SRAGs, e que devido a fatores operacionais, sistemáticos e, principalmente políticos, nos encontramos frente a dados que são subutilizados, obstruindo o funcionamento adequado do sistema de saúde, e trazendo grandes incertezas.

\section{CONSIDERAÇÕES FINAIS}

A cada dia, desde o início da pandemia, novos estudos e análises são divulgados a respeito das novidades acerca da COVID-19. Dentre eles, foi possível notar o uso dos dados da SRAG para avaliar a real dimensão da doença no mundo todo. Através das plataformas consolidadas a partir da vigilância epidemiológica da Influenza, é possível realizar o levantamento de dados acerca dos números da SRAG, que são capazes de transparecer um panorama mais fidedigno da COVID-19 no país, contribuindo para a pesquisa e consequente tomada de decisões.

O sistema SIVEP-Gripe aparece destacado nesse momento, e portanto, considerando as possíveis falhas, é uma base de dados que compreende todo o território brasileiro no nível municipal, permitindo que revele-se a público a evolução da doença em seu determinado município. Aliando-se a outras fontes de dados as possibilidades de análise se expandem consideravelmente. Dessa forma, foi possível visualizar a hipótese da subnotificação, que vem sendo discutida desde o início da pandemia, e que se apresenta como um contratempo na busca pelo controle da doença no país. Tratar destes dados no panorama sul-mineiro de forma consistente pode contribuir para a projeção de cenários futuros, para a compreensão da velocidade da difusão e, sobretudo, para a tomada de decisões, bem como, na elaboração de políticas públicas mais efetivas para o enfrentamento da pandemia.

Como temos ressaltado ao longo do texto, é fato que a saúde e toda complexidade que este sistema compreende, configura-se como uma questão de escolha política. A postura governamental diante da pandemia demonstra-se deliberadamente negligente. Entre o menosprezo e o negacionismo, sua diretriz fundamental tem se concentrado em minimizar os efeitos da pandemia como mecanismo para legitimar políticas econômicas em detrimento de uma política mais efetiva de enfrentamento do seu avanço. O cargo vago de Ministro da Saúde durante pelo menos três meses é sintomático dessa postura supramencionada.

Outra constatação importante nesse debate é que hoje o Brasil configura-se como um dos países com mais baixa testagem. Isso se manifesta na relação de um caso positivo para cada três testes realizados, número sete vezes menor que o recomendado pela OMS, e ainda assim está entre os três países com mais casos, além de possuir oficialmente $3,8 \%$ de sua população contaminada com o novo coronavírus. A dimensão da tragédia sanitária brasileira só pode ser compreendida em sua relação com a forma como o governo protofascista se 
posicionou. Governo este que de forma consciente e sistemática sabotou todas iniciativas de isolamento social, desestimulou os cuidados necessários, estimulou a contaminação ilimitada, bem como, atacou a ciência e o conhecimento, propagando a desinformação e o negacionismo.

Segundo o estudo realizado pela Faculdade de Saúde Pública da USP e pela Conectas Direitos Humanos (organização de justiça da América Latina), que analisou 3.049 normas federais produzidas no ano de 2020, existe uma deliberada "estratégia institucional de propagação do vírus, promovida pelo Governo brasileiro sob a liderança da Presidência da República" (EL PAÍS BRASIL, 2020). O estudo ainda revela que:

os resultados afastam a persistente interpretação de que haveria incompetência e negligência de parte do governo federal na gestão da pandemia. Bem ao contrário, a sistematização de dados (...) revela o empenho e a eficiência da atuação da União em prol da ampla disseminação do vírus no território nacional, declaradamente com o objetivo de retomar a atividade econômica o mais rápido possível e a qualquer custo (EL PAÍS BRASIL, 2021, online) (grifos nossos).

Ou seja, não se trata de mera incompetência, o estudo demonstrou que há intencionalidade, planejamento e ação sistemática nas normas do Governo e nas manifestações de Bolsonaro. Trata-se de uma decisão política a disseminação do vírus, como acompanhado no Brasil. O número assustador de mortes no Brasil pelo coronavírus, que já ultrapassam a marca de 220 mil (até 29 de janeiro de 2021), é consequência de uma estratégia política. Negar o problema parece ter sido mais barato que enfrentá-lo (tanto economicamente como politicamente). A pesquisa da USP também afirma que "a maioria das mortes seriam evitáveis por meio de uma estratégia de contenção da doença, o que constitui uma violação sem precedentes do direito à vida e do direito à saúde dos brasileiros" (EL PAÍS BRASIL, 21/01/2021).

Além disso, diante da única alternativa verdadeiramente comprovada cientificamente de enfrentamento da doença, que seria a imunização da população por meio da vacinação, "Bolsonaro anuncia que não vai se vacinar e atua para criar pânico na população, referindo-se a terríveis efeitos colaterais". Para além da desinformação Bolsonaro ainda vetou parte da Lei Complementar $\mathrm{n}^{\mathrm{o}} 177$, de 12 de janeiro de 2020, aprovada por ampla maioria no Senado (71 votos a favor contra apenas um voto contra) e na Câmara dos Deputados (385 x 18 votos). Segundo a Agência FAPESP, os "vetos presidenciais subtraem 9,1 bilhões de reais dos investimentos em ciência, tecnologia e inovação neste ano, impedindo que o Brasil desenvolva uma vacina contra a Covid-19, apesar de ter infraestrutura e recursos humanos suficientes" (EL PAÍS BRASIL, 21/01/2021).

Esses atos de desinformação e as inúmeras decisões políticas tomadas por este Governo, já estão custando e ainda vão custar centenas de milhares de vidas humanas. Esta condição não se restringe aos atos presidenciais, mas transborda pela institucionalidade estatal em seus mecanismos de levantamento e sistematização de dados. Isso evidentemente se 
estende para os âmbitos estaduais e municipais e atende muito bem aos interesses daqueles que priorizam uma abertura irrestrita da atividade econômica. E isto cabe muito bem para o caso do estado de Minas Gerais e, para nossa análise, na região sul-mineira.

Por fim, ressalta-se que não é válida e não pode ser compreendida como séria, uma interpretação dessa condição como mero equívoco institucionalizado, uma "falha no sistema", ou uma interpretação possível. Os números acompanhados de sua série histórica, como apresentado ao longo deste estudo, são expressivos e taxativos. A partir deles é possível a constatação de que tal escamoteamento sistemático é deliberado e esconde intencionalidades políticas. O que precisa ser evidenciado, por conseguinte, é que, se a saúde pública, como bem demonstrado, configura-se como uma dimensão política que envolve escolhas e decisões, é evidente que, nessas circunstâncias, a grande responsabilidade pelo número de mortes é consequentemente parte dessa escolha e dessas decisões governamentais.

\section{NOTAS}

- Monitora COVID-19. Disponível em: $<\underline{\text { https://bigdata-covid19.icict.fiocruz.br/ }>\text { Acesso }}$ em: 24 jul 2020.

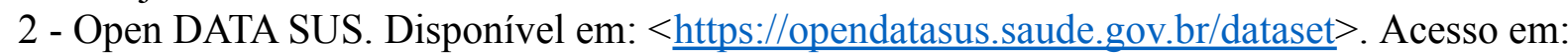
26 ago 2020.

3 - Até a conclusão da elaboração deste artigo, as atualizações eram feitas a cada 6 ou 7 dias através do Open Data SUS.

\section{REFERÊNCIAS}

BACKHAUS, A. Common Pitfalls in the Interpretation of COVID-19 Data and Statistics. Intereconomics, v. 55, 2020, p. $162-166$.

BASTOS, L. S.; et al. COVID-19 e hospitalizações por SRAG no Brasil: uma comparação até a 12a semana epidemiológica de 2020. Cadernos de Saúde Pública, [S.L.], v. 36, n. 4, p. 1-8, 2020. FapUNIFESP (SciELO).

BRASIL. Lei n $^{\circ} 8.080$ de 19 de setembro de 1990. Dispõe sobre as condições para a promoção, proteção e recuperação da saúde, a organização e o funcionamento dos serviços correspondentes e dá outras providências. Brasília: Congresso Nacional. Disponível em: <https://www.planalto.gov.br/ccivil_03/leis/18080.htm> Acesso em: 24 ago. 2020.

BRUM, E. Pesquisa revela que Bolsonaro executou uma "estratégia institucional de propagação do coronavírus". EL PAÍS Brasil, $2020 . \quad$ Disponível em: $<$ https://brasil.elpais.com/brasil/2021-01-21/pesquisa-revela-que-bolsonaro-executou-uma-estrategia-institucional-de-propaga cao-do-virus.html> Acesso em 21 de janeiro de 2021.

DE SOUZA, W.M., BUSS, L.F., CANDIDO, D.D.S. et al. Epidemiological and clinical characteristics of the COVID-19 epidemic in Brazil. Nat Hum Behav 4, 856-865 (2020). https://doi.org/10.1038/s41562-020-0928-4

DUDH. Declaração Universal dos Direitos Humanos das Nações Unidas (1948): Unic/Rio, 2009. In: https://nacoesunidas.org/wp-content/uploads/2018/10/DUDH.pdf. Acesso em 30 de agosto de 2020

FUNDAÇÃO OSWALDO CRUZ. Plataforma Monitora COVID-19. Rio de Janeiro: FioCruz, 2020. Disponível em: $<$ https://bigdata-covid19.icict.fiocruz.br/>. Acesso em: 11 jan. 2021.

FUNDAÇÃO OSWALDO CRUZ. Vigilância em saúde. Disponível em: <https://pensesus.fiocruz.br/vigilancia-em-saude> Acesso em 11 jan. 2021. 
IBGE. Divisão regional do Brasil em mesorregiões e microrregiões geográficas. Rio de Janeiro: IBGE, 1990.

INSTITUTO TRICONTINENTAL DE PESQUISA SOCIAL. Saúde, uma Escolha Política. Dossiê n 29. Junho de 2020.

MEGDA, J.D.L., BONAFÉ, S.M. Subnotificação de doenças infecciosas como realidade do sistema de saúde brasileiro. Anais. VIIIIII EPCC UNICESUMAR - Centro Universitário Cesumar. Maringá, 2013.

MINAS GERAIS. SES/MG. Boletim epidemiológico COVID-19. Disponível em: http://coronavirus.saude.mg.gov.br/boletim. Acesso em: 11 jan 2021.

MINISTÉRIO DA SAÚDE. SIVEP-GRIPE: dados abertos. Brasília: Ministério da Saúde, 2006. Disponível em: $<$ https://datasus.saude.gov.br/>. Acesso em: 11 jan 2021.

NIQUINI, Roberta Pereira; LANA, Raquel Martins; PACHECO, Antonio Guilherme; CRUZ, Oswaldo Gonçalves; COELHO, Flávio Codeço; CARVALHO, Luiz Max; VILLELA, Daniel Antunes Maciel; GOMES, Marcelo Ferreira da Costa; BASTOS, Leonardo Soares. SRAG por COVID-19 no Brasil: descrição e comparação de características demográficas e comorbidades com srag por influenza e com a população geral. Cadernos de Saúde Pública, [S.L.], v. 36, n. 7, p. 1-12, 2020. FapUNIFESP (SciELO). http://dx.doi.org/10.1590/0102-311x00149420.

RIBEIRO, I. G.; SANCHEZ, M. N. Avaliação do sistema de vigilância da síndrome respiratória aguda grave (SRAG) com ênfase em influenza, no Brasil, 2014 a 2016*. Epidemiologia e Serviços de Saúde, [S.L.], v. 29, n. 3, p. 1-13, jun. 2020. FapUNIFESP (SciELO). r.

\section{COMO CITAR ESTE TRABALHO}

CAETANO, J.M. CASEMIRO, F.H.C.Saúde como escolha política: SRAG e subnotificação nas cidades sul mineiras. Revista Tamoios, São Gonçalo, v. 17, n. 2, p. 187-205, 2021.Disponível em: https://doi.org/10.12957/tamoios.2021.57476. Acesso em: DD MM. AAAA. 